\title{
Enantioselective Synthesis of 6,6-Disubstituted Pentafulvenes Containing a Chiral Pendant Hydroxy Group
}

Ryan Nouch, Melchior Cini, Marc Magre, Mohammed Abid, Montserrat Diéguez, $\dagger$ Oscar Pàmies, Simon Woodward,* and William Lewis

[*]R. Nouch, Dr. M. Cini, M. Abid, Prof. Dr. S. Woodward, Dr. W. Lewis, GlaxoSmithKline Carbon Neutral Laboratories for Sustainable Chemistry, University of Nottingham, 6 Triumph Road, Nottingham, NG7 2GA (United Kingdom)

Email: simon.woodward@nottingham.ac.uk

[†]M. Magre, Prof. Dr. M. Diéguez, Prof. Dr. O. Pàmies, Departament de Química Física i Inorgànica, Universìtat Rovira i Virgili, Campus Sescelades, Marcel, lí Domingo 1 - 43007, Tarragona (Spain)

E-mail: montserrat.dieguez@urv.cat

Abstract: Simple enantioselective synthesis of 6,6-disubstituted pentafulvenes bearing chiral pendant hydroxy groups are attained by cascade reactivity using commercially available proline-based organocatalysts. Condensation of cyclopentadiene with the acetyl function of a 1,2formylacetophenone, followed by cyclization of a resulting fulvene-stabilized carbanion with the formyl group, generates bicyclic chiral alcohols with initial er values up to 94:6. Exceptional enantioenrichment of the resultant alcohols results upon crystallization - even near racemic samples spontaneously de-racemize. This enables new families of substituted cyclopentadienes that are both enantiomerically and diastereomerically pure to be rapidly attained.

Synthetic methodology for pentafulvene formation has not altered significantly since these were first prepared by Thiele in 1900 by sodium ethoxide facilitated condensation of cyclopentadiene with ketones (Scheme 1) ${ }^{[1]}$ Although improved by Little ${ }^{[2]}$ and Ottosson ${ }^{[3]}$ among others none of these allows access to chiral fulvenes. Little's method uses pyrrolidine catalysis to increase the reactivity of the ketone, whilst Ottosson's method uses sodium cyclopentadienide as a more reactive source of the cyclopentadiene nucleophile. Both approaches allow for the reaction of more hindered or less activated carbonyls. Across the board, examples of syntheses of pentafulvenes bearing chiral pendant functional groups are almost unknown, one rare example being Togni's condensation of sodium cyclopentadienide with a homochiral amide (Scheme 1). ${ }^{[4]}$ Unfortunately, this method was limited in scope as only two chiral examples of singly substituted 6-derivatives could be accessed. Despite a complete lack of effective stereoselective syntheses, pentafulvenes remain a commonly used compound class. Frequent applications include: cycloadditions to generate complex, polycyclic scaffolds ${ }^{[5][6]}$ and their use as intermediates in the synthesis of substituted (sometimes chiral) cyclopentadienyl derivatives via nucleophilic addition to the exocyclic $\mathrm{C}=\mathrm{C}$ bond as a route to (asymmetric) cyclopentadiene units. ${ }^{[7][8][9]}$ Herein we describe a simple approach to families of asymmetric 6,6-disubstituted pentafulvenes bearing chiral pendant hydroxy groups (for further functionalization) by straightforward organocatalytic methodology. The pentafulvenes are useful as intermediates in the synthesis of substituted cyclopentadienes as single enantiomers and diastereomers. 

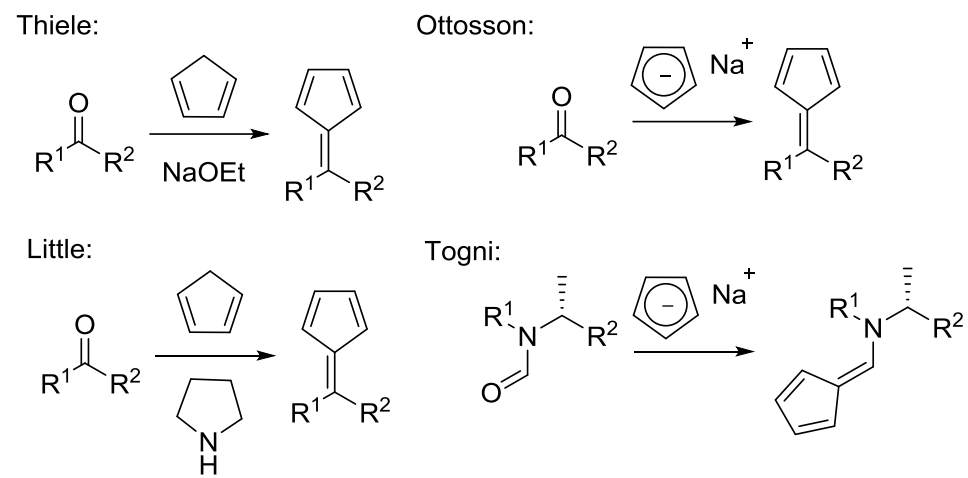

Scheme 1. Traditional approaches to (chiral) 6,6- and 6-substituted pentafulvenes.

To develop a route to new chiral pentafulvenes bearing pendant hydroxy groups, we investigated the reaction between 2-acetyl-benzaldehyde and cyclopentadiene in the presence of organocatalysts (Table 1). Reference samples of $( \pm)$-2a were prepared via pyrrolidine catalysed reactions, although these were slower than the later enantioselective reactions (see Table S1 - Supporting Information). Interestingly, we noted that $( \pm)$-2a de-racemizes exceptionally readily, with each crystal being a single enantiomer, in the same manner as the classical tartrate crystals of Pasteur. ${ }^{[10][11]}$ Single individual crystals of $(R)$ or $(S)$-2a are readily attained stochastically from initially racemic ( \pm )-2a. This occurs predictably for scalemic 2a making exceptional enantio-enrichment possible. Conglomerate crystal formation in 2a is driven by a strongly stereodirecting helical hydrogen bonding array in its packing (see Figure S5 Supporting Information). Simple (L)-proline gave only low yields of 2a, but greater success was had with derivatives of $(S)$-2-pyrrolidinemethanol $\left(\mathbf{L}_{\mathbf{A}}\right)$. Smaller amounts of achiral $\mathbf{3}$ and aldol product $\mathbf{4}$ could also be isolated from the reaction. Compound $\mathbf{4}$ is a known product of $\mathbf{1 a}$ (formed in low er in asymmetric aldol chemistry ${ }^{[12]}$ ) but the preparation of pentafulvene products of type $\mathbf{2}$ is unprecedented, as far as we are aware. Catalysts bearing too much steric bulk, such as $\mathbf{L}_{\mathrm{E}}$ or the bulky diaryl derivatives developed by Jørgenson ${ }^{[12]}$ and Hayashi ${ }^{[13]}$ proved ineffective as did the imidazolidinone derivatives of Macmillan. ${ }^{[14]}$ Optimal results were attained with (2S)-1-(pyrrolidin-2-ylmethyl)pyrrolidine $\left(\mathbf{L}_{\mathbf{B}}\right){ }^{[15][16]}$ with a reduced number of equivalents of acetic acid ( 0.13 vs. 0.38 equiv.). Below 0.38 equivalents of catalyst $\mathbf{L}_{\mathbf{B}}$ the reaction conversion suffered but the er remained high. Alternative acids were also trialled but all performed worse than acetic acid in the reaction (see Table S1 - Supporting Information). The reaction could be scaled to gram quantities without any significant negative yield or er effects (see Experimental Section). Excesses of cyclopentadiene were employed, as it is cheap and easily removed during purification, to ensure reliability of the reaction and disfavour the production of by-product 4 as much as possible.

Table 1. Summary of optimization for enantioselective preparation of pentafulvene $\mathbf{2 a}^{[\mathrm{a}]}$ 

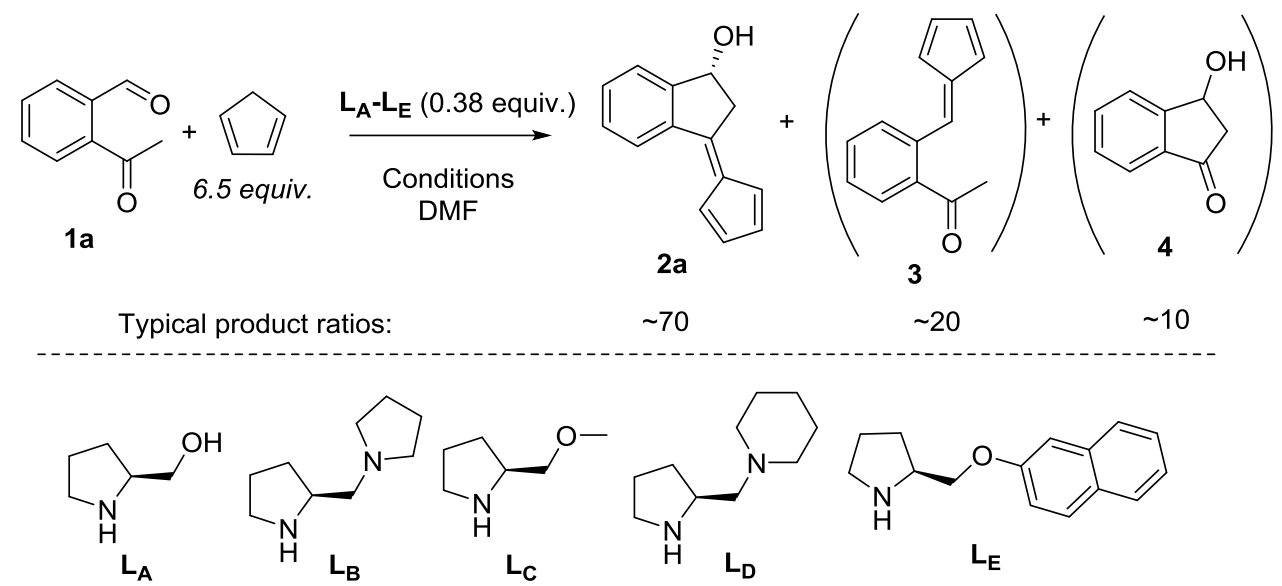

\begin{tabular}{cccccc}
\hline Catalyst & Acid (equiv.) & Time $(\mathrm{h})$ & Temperature $\left({ }^{\circ} \mathrm{C}\right)$ & Yield $^{[\mathrm{b}]}(\%)$ & $e r$ \\
\hline $\mathbf{L}_{\mathbf{A}}$ & AcOH $(0.38)$ & 24 & 25 & $90^{[\mathrm{c}]}$ & $79: 21$ \\
$\mathbf{L}_{\mathbf{B}}$ & $\operatorname{AcOH}(0.38)$ & 2 & 25 & 71 & $86: 14$ \\
$\mathbf{L}_{\mathbf{B}}$ & $\operatorname{AcOH}(0.26)$ & 2 & 22 & 76 & $89: 11$ \\
$\mathbf{L}_{\mathbf{B}}$ & $\operatorname{AcOH}(0.13)$ & 6 & 15 & $\mathbf{7 8}$ & $\mathbf{9 4 : 6}$ \\
$\mathbf{L}_{\mathbf{C}}$ & $\operatorname{AcOH}(0.13)$ & 24 & 22 & 69 & $80: 20$ \\
$\mathbf{L}_{\mathbf{D}}$ & $\operatorname{AcOH}(0.13)$ & 2 & 22 & 71 & $90: 10$ \\
$\mathbf{L}_{\mathbf{E}}$ & $\operatorname{AcOH}(0.13)$ & 4 & 22 & $<5$ & n.d. ${ }^{[\mathrm{d}]}$ \\
\hline
\end{tabular}

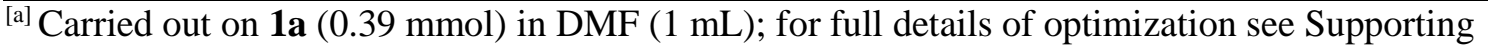
Information. ${ }^{[b]}$ Isolated yield unless otherwise stated. ${ }^{[c]}$ Conversion determined by ${ }^{1} \mathrm{H}$ NMR spectroscopy with no internal standard present (mass balance of $>90 \%$ confirmed independently). ${ }^{[d]}$ Not determined.

The precursor 2-acetyl-benzaldehydes (1a-1i) needed for generalization of the reaction are easily prepared on multi-gram scales via two routes. Directed lithiation of a range of benzyl alcohols followed by reaction with acetaldehyde and subsequent oxidation provides 1a-c in two steps. Alternatively, Phan's phenol formylation, followed by acyl hydrazide formation and subsequent acyl transfer was used for $\mathbf{1 d - i}{ }^{[17]}$ The optimal catalyst $\mathbf{L}_{\mathbf{B}}$ is commercially available, but also readily and efficiently prepared on multi-gram scales, starting from low cost $(L)$-proline via our optimized method (see Supporting Information). The generality of the reaction was thus explored (Table 2).

Table 2. Substrate scope for chiral pentafulvene (2) formation. ${ }^{[a]}$ 


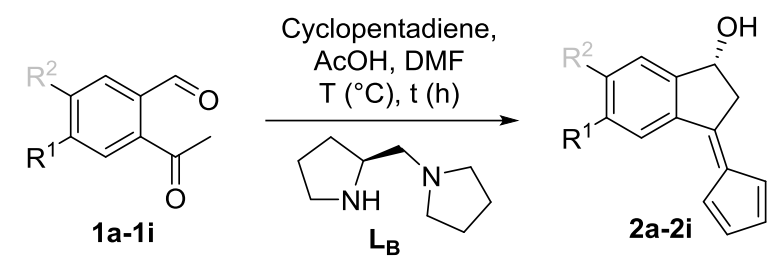

\begin{tabular}{cccccccc}
\hline Compound & $\mathrm{R}^{1}$ & $\mathrm{R}^{2}$ & $\mathrm{~T}\left({ }^{\circ} \mathrm{C}\right)$ & $\mathrm{T}(\mathrm{h})$ & $\begin{array}{c}\text { Yield }^{[\mathrm{b}]} \\
(\%)\end{array}$ & Initial er & Recrystallized er \\
\hline $\mathbf{2 a}$ & $\mathrm{H}$ & $\mathrm{H}$ & 15 & 6 & 78 & $94: 6$ & $>99: 1$ \\
$(\boldsymbol{S}) \mathbf{- 2} \mathbf{a}^{[\mathrm{d}]}$ & $\mathrm{H}$ & $\mathrm{H}$ & 15 & 6 & 65 & $94: 6$ & $98: 2$ \\
$\mathbf{2 b}$ & $\mathrm{Ph}$ & $\mathrm{H}$ & 15 & 4.5 & 53 & $88: 12$ & $>99: 1$ \\
$\mathbf{2 c}$ & $t \mathrm{Bu}$ & $\mathrm{H}$ & 22 & 2.5 & 91 & $82: 18$ & -[c] \\
$\mathbf{2 d}$ & $\mathrm{Me}$ & $\mathrm{H}$ & 15 & 6 & 72 & $91: 9$ & -[c] \\
$\mathbf{2 e}$ & $\mathrm{OMe}$ & $\mathrm{H}$ & 15 & 5 & 54 & $91: 9$ & $>99: 1$ \\
$\mathbf{2} \mathbf{f}$ & $\mathrm{F}$ & $\mathrm{H}$ & 25 & 4.5 & 39 & $92: 8$ & $>99: 1$ \\
$\mathbf{2 g}$ & $\mathrm{H}$ & $\mathrm{Me}$ & 15 & 6 & 67 & $89: 11$ & -[c] \\
$\mathbf{2 h}$ & $\mathrm{H}$ & $\mathrm{F}$ & 25 & 3 & 52 & $88: 12$ & $>99: 1$ \\
$(\boldsymbol{S})-\mathbf{2} \mathbf{h}^{[\mathrm{d}]}$ & $\mathrm{H}$ & $\mathrm{F}$ & 25 & 3 & 39 & $90: 10$ & $>99: 1$ \\
$\mathbf{2 i}$ & $\mathrm{H}$ & $\mathrm{Cl}$ & 25 & 3 & 38 & $91: 9$ & $99: 1$ \\
$(\boldsymbol{S})-\mathbf{2 i} \mathbf{i}^{[\mathrm{d}]}$ & $\mathrm{H}$ & $\mathrm{Cl}$ & 25 & 2.5 & 30 & $89: 11$ & $99: 1$ \\
\hline
\end{tabular}

${ }^{\text {[a] }}$ Carried out on 1 (0.6-2.1 mmol) with $\mathrm{AcOH}$ (0.13 equiv.) and $\mathbf{L}_{\mathbf{B}}(0.38$ equiv.) in DMF $(1-5 \mathrm{~mL})$; for full details see Supporting Information. ${ }^{[b]}$ Isolated yield. ${ }^{[c]}$ Could not be enriched by recrystallization. ${ }^{[\mathrm{d}]}$ Synthesized under identical conditions but providing the $(S)$-pentafulvene using $(\boldsymbol{R})-\mathbf{L}_{\mathbf{B}}$.

Fulvene formation is tolerant of a range of electronic substituent effects in the 5-position (2d-f) but is more sensitive to steric factors (runs $\mathbf{2 b}$-c). The opposite situation applies to substitution in the 6position (runs $2 \mathbf{g}-\mathbf{i}$ ). The poorer yields obtained for halogen containing $2 \mathbf{f}$ and $2 \mathbf{i}$ appear to be due to the decreased stability of the product rather than lower conversion based on control experiments. Modification of the reaction conditions allowed isolation of the two by-products $\mathbf{3}$ and $\mathbf{4}$ in useful quantities. Reduction of the reaction temperature to $0{ }^{\circ} \mathrm{C}$ provided condensation by-product 3 in $45 \%$ yield after 48 hours. We propose that this is due to the lower temperature strongly disfavoring the less reactive keto functionality, allowing for an increase in condensation between the more reactive aldehyde and cyclopentadiene longer reaction times. Running the reaction under its optimized conditions (Table 1, Run 4) but without added cyclopentadiene resulted in a 55\% isolated yield of aldol by-product $(S)-4$ $(e r<85: 15)$. Isolation of these by-products enabled us to unambiguously define the reaction mechanism for pentafulvene formation (Scheme 2). Pathway A can be discounted as intermediate $\mathbf{5}$ would produce aldol by-product $\mathbf{4}$, however, resubmission of isolated $\mathbf{4}$ to the reaction conditions produces no fulvene products discounting cyclopentadiene condensation at the keto group of $\mathbf{4}$. In addition, HPLC confirms the chiral centre in $(S)-\mathbf{4}$ is of opposite configuration to the $(R)-\mathbf{2}$ provided by $\mathbf{L}_{\mathbf{B}}$, eliminating $\mathbf{4}$ as a simple precursor to $2{ }^{[18][19]}$ Similarly, pathway $C$ can be discounted on the fact that resubmission of isolated $\mathbf{3}$ to the reaction conditions also produces no $\mathbf{2}$, disavowing potential intermediates in the $\mathrm{H}$ shift pathway 7a-b. In addition, pathway $\mathrm{C}$ would provide regioisomeric 2' (Scheme 2) if appropriately substituted (regardless of the sense of asymmetric induction). Only pathway B, in which condensation of cyclopentadiene with the acetyl ketone occurs first, correctly accounts for both the regiochemistry and sense of stereochemistry observed in the reaction. The acidity of the $\alpha$-methyl fulvene group ( $\mathrm{pK}_{\mathrm{a}}$ ca. 22.1 in $\mathrm{DMSO}^{[20]}$ ) and the subsequent inversion in the $\mathrm{S}_{\mathrm{N}} 1$-like cleavage of the amine both have precedent. ${ }^{[2][22][23]}$ Intermediates $\mathbf{6 a - b}$ could not be isolated or detected but remain the only viable option consistent with the experimental data. Large leaving groups, as in $\mathbf{6 b}$, strongly favour inversion 
outcomes in $\mathrm{S}_{\mathrm{N}} 1$ hydrolysis reactions and an ability for additional protonation of the pyrrolidine nitrogen may account for the improved performance of $\mathbf{L}_{\mathbf{B}}$.

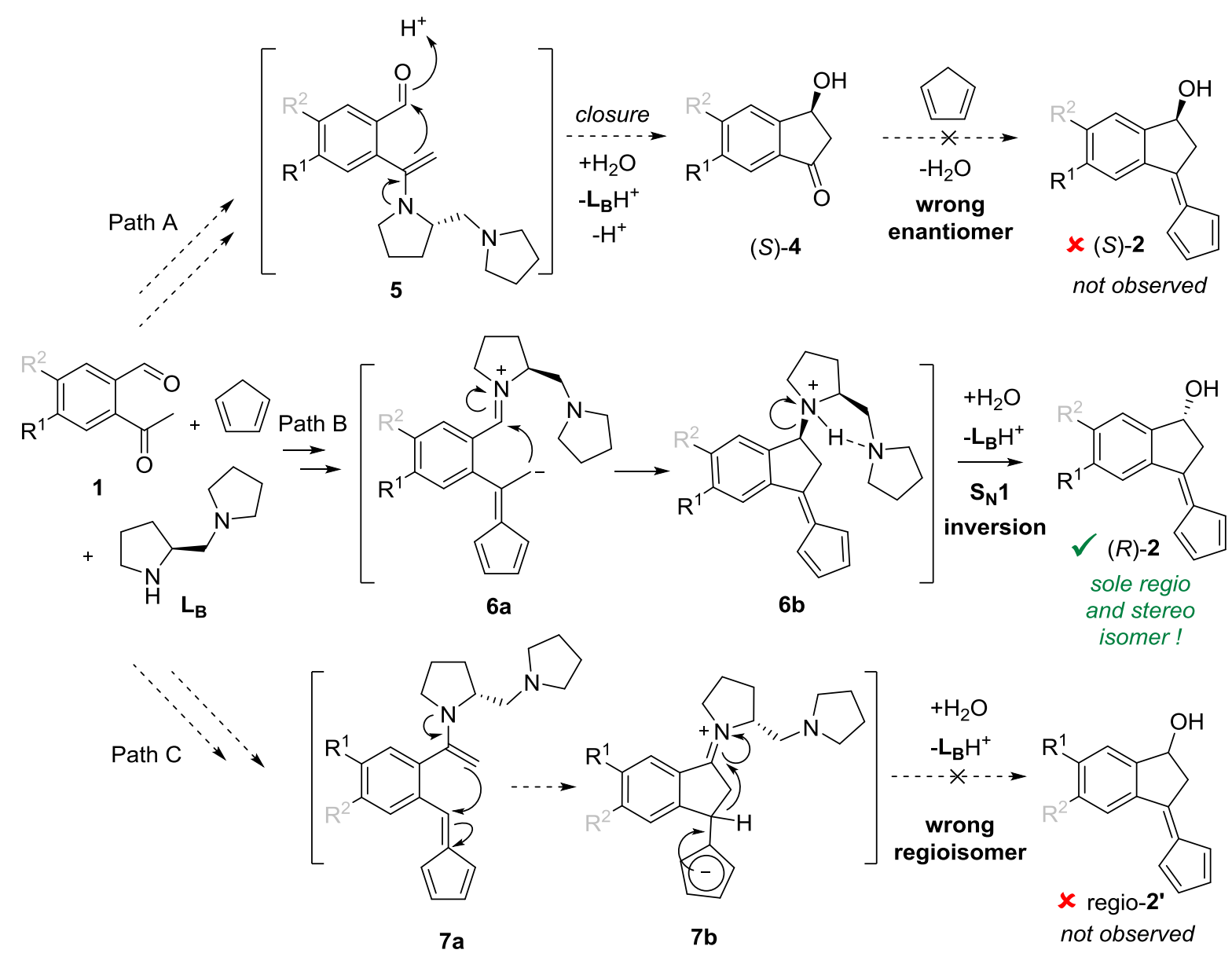

Scheme 2. Mechanistic possibilities for the formation of pentafulvene 2a.

Preliminary studies show that, following functionalization of the pendant hydroxy group, pentafulvenes of type 2 can be reduced, in the manner of Tacke, ${ }^{[24]}$ using $\mathrm{LiBEt}_{3} \mathrm{H}$. One example of this is shown in Scheme 3 . The reduction proceeds with very high diastereoselectivity $(>25: 1$ as the other diastereomer is not visible in the ${ }^{1} \mathrm{H}$ NMR spectrum) following functionalization of pentafulvene $\mathbf{2 a}$ with triethylsilyl chloride (TESCl). The silyl ether moiety acts as a blocking group, forcing the hydride to add anti to it, resulting in the synthesis of syn-cyclopentadiene 9 (see Supporting Information, Figure S2, for an explanation of the structural assignment of $\mathbf{9}$ ). 


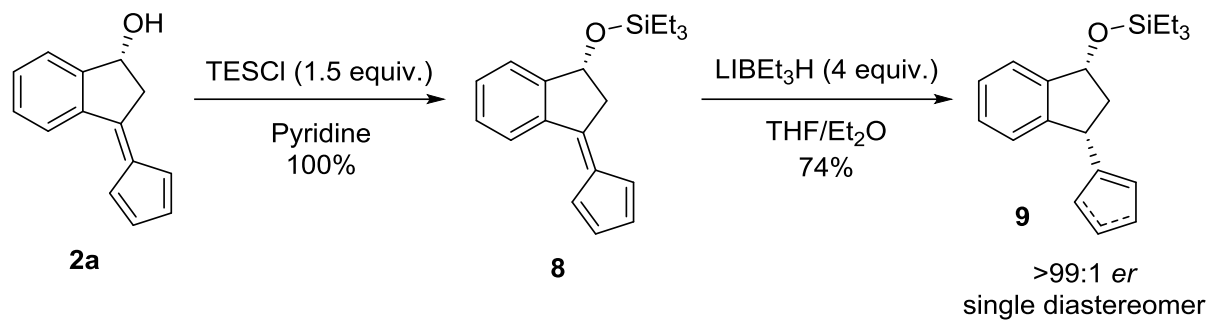

Scheme 3. Synthesis of protected pentafulvene $\mathbf{8}$, via the reaction of pentafulvene $\mathbf{2 a}$ with TESCl, which is then reduced to syn cyclopentadiene $\mathbf{9}$. The double bond tautomers of $\mathbf{9}$ are removed upon metal complexation.

To conclude, we have presented an efficient synthesis of chiral 6,6-disubstituted pentafulvenes bearing a functionalizable chiral pendant hydroxy group in moderate to good yields and enantiomeric ratios. These pentafulvenes possess the interesting and useful characteristic of crystallizing as conglomerates, often giving the products in >99:1 er at gram scales. Once functionalized, these chiral pentafulvene derivatives can then be converted into substituted cyclopentadienes essentially as both single enantiomers and diastereomers.

\section{Experimental Section:}

Representative procedure for synthesis of pentafulvene (R)-2a: Commercially available 2-acetylbenzaldehyde ( $1.29 \mathrm{~g}, 78 \%$ purity, $6.79 \mathrm{mmol})$ and cyclopentadiene $(3.6 \mathrm{~mL}, 42.8 \mathrm{mmol})$ were dissolved in DMF $(16.0 \mathrm{~mL})$ before the addition of acetic acid $(47 \mu \mathrm{L}, 0.82 \mathrm{mmol})$ and dropwise addition of commercially available (2S)-1-(pyrrolidin-2-ylmethyl)pyrrolidine (411 $\mu \mathrm{L}, 2.52 \mathrm{mmol})$. This was then stirred at $15{ }^{\circ} \mathrm{C}$ for 6 hours, after which the reaction was diluted into ethyl acetate (250 $\mathrm{mL})$ and washed with $\mathrm{pH} 7.4$ phosphate buffer $(3 \times 100 \mathrm{~mL})$. The solvent was removed in vacuo before purification via flash column chromatography (eluent: dichloromethane) to yield the crude product as a bright orange solid in $64 \%$ yield $(850 \mathrm{mg}, 4.33 \mathrm{mmol})$; yield range on $0.1-1 \mathrm{~g}$ scales: $64-78 \%$. Purification from $\mathrm{CH}_{2} \mathrm{Cl}_{2}$ /pentane, or dimethoxyethane readily afforded $(R)-\mathbf{2 a}$ as red needles $(590 \mathrm{mg}$, $3.01 \mathrm{mmol}, 70 \%$ recovery) with $>99: 1$ er. M.p.: $130-140{ }^{\circ} \mathrm{C}$ (darkens from this temperature); $\mathbf{R}_{\mathbf{f}}$ (dichloromethane): $0.30 ;{ }^{1} \mathbf{H}$ NMR $\left(400.2 \mathrm{MHz}, \mathrm{CDCl}_{3}\right): \delta_{\mathrm{H}} 7.96(\mathrm{dd}, J=6.6,1.9 \mathrm{~Hz}, 1 \mathrm{H}, \mathrm{Ar} H)$, 7.58$7.55(\mathrm{~m}, 1 \mathrm{H}, \operatorname{Ar} H), 7.48-7.38(\mathrm{~m}, 2 \mathrm{H}, \operatorname{Ar} H), 6.92(\operatorname{app} \mathrm{ddd}, J=5.3,1.7,1.7 \mathrm{~Hz}, 1 \mathrm{H}, \mathrm{CpH}), 6.59-6.55$ (m, $1 \mathrm{H}, \mathrm{CpH}), 6.53-6.49$ (m, 2H, CpH), 5.35 (ddd, $J=7.0,7.0,3.7 \mathrm{~Hz}, 1 \mathrm{H}, \mathrm{CHOH}), 3.72$ (dd, $J=17.5$, $7.0 \mathrm{~Hz}, 1 \mathrm{H}, \mathrm{CH}_{\mathrm{a}} \mathrm{H}_{\mathrm{b}}$ anti to $\left.\mathrm{OH}\right), 3.09$ (dd, $J=17.5,7.0 \mathrm{~Hz}, 1 \mathrm{H}, \mathrm{CH}_{\mathrm{a}} H_{\mathrm{b}} s y n$ to $\left.\mathrm{OH}\right), 2.01(\mathrm{~d}, J=3.7 \mathrm{~Hz}$, $1 \mathrm{H}, \mathrm{OH}) ;{ }^{13} \mathrm{C}$ NMR $\left(100.05 \mathrm{MHz}, \mathrm{CDCl}_{3}\right): \delta_{\mathrm{C}} 151.2(\mathrm{C}), 149.5(\mathrm{C}), 139.4(\mathrm{C}), 138.7(\mathrm{C}), 132.8(\mathrm{CH})$, $131.1(\mathrm{CH}), 131.0(\mathrm{CH}), 129.4(\mathrm{CH}), 126.5(\mathrm{CH}), 125.4(\mathrm{CH}), 123.4(\mathrm{CH}), 120.0(\mathrm{CH}), 72.9(\mathrm{CH}), 44.0$ $\left(\mathrm{CH}_{2}\right)$; v $\mathbf{v}_{\max }\left(\mathrm{CHCl}_{3}\right): 3614,3590,3070,3045,3008,2960,2927,2873,1630,1476,1458,1389,1368$, 1239, 1050, 1021, $997 \mathrm{~cm}^{-1}$; HRMS found $197.0959 \mathrm{C}_{14} \mathrm{H}_{13} \mathrm{O}^{+}$requires $197.0961(|\sigma|=1.0 \mathrm{ppm})$; HPLC (before crystallization): Chiralpak AD-H; mobile phase, hexane:2-propanol (4:1 v/v); flow rate, $0.5 \mathrm{~mL} \cdot \mathrm{min}^{-1}$; retention times $(S)$ enantiomer: $11.8 \mathrm{~min}(6.2 \%),(R)$ enantiomer: $14.2 \mathrm{~min}(93.8 \%)$, er 94:6; $[\alpha]_{\mathbf{D}}{ }^{23}:+68.0\left(e r>99: 1, c=0.50\right.$ in $\left.\mathrm{CHCl}_{3}\right)$; Anal: Calcd. for $\mathrm{C}_{14} \mathrm{H}_{12} \mathrm{O} \mathrm{C}, 85.68 \% ; \mathrm{H}, 6.16 \%$; found $\mathrm{C}, 85.20 \% ; \mathrm{H}, 6.47 \%$.

\section{Acknowledgments}

We thank the Edith Johnson Bequest Fund and Aesica Pharmaceuticals for partial support of the University of Nottingham studentships of MC and RN respectively. MA is grateful to the University of Anbar (Iraq) for PhD study leave (award IDB600032695). MM, MD and OP thank the Spanish Ministry of Economy and Competitiveness (CTQ2016-74878-P) and European Regional Development Fund 
(AEI/FEDER, UE), the Catalan Government (2014SGR670), and the ICREA Foundation (ICREA Academia award to MD) for financial support.

Graphical Abstract

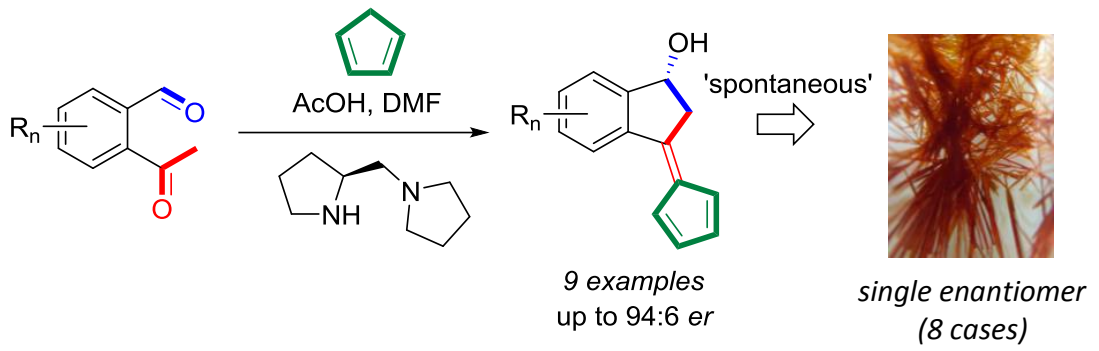

Keywords: Asymmetric Catalysis • Organocatalysis • Asymmetric Amplification • Synthetic Methods

- Fulvene

\section{References}

[1] J. Thiele, Ber. dtsch. chem. Ges 1900, 33, 666-673.

[2] K. J. Stone, R. D. Little, J. Org. Chem 1984, 49, 1849-1853.

[3] K. Chajara, H. Ottosson, Tetrahedron Lett. 2004, 45, 6741-6744.

[4] H. C. L. Abbenhuis, U. Burckhardt, V. Gramlich, A. Togni, A. Albinati, B. Mueller, Organometallics 1994, 13, 4481-4493.

[5] Z. Zhou, Z.-X. Wang, Y.-C. Zhou, W. Xiao, Q. Ouyang, W. Du, Y.-C. Chen, Nat. Chem. 2017, 1-5.

[6] Z. J. Jia, C. Merten, R. Gontla, C. G. Daniliuc, A. P. Antonchick, H. Waldmann, Angew. Chemie., Int. Ed. 2017, 56, 2429-2434.

[7] M. Cini, T. D. Bradshaw, W. Lewis, S. Woodward, Eur. J. Org. Chem. 2013, 3997-4007.

[8] M. Cini, T. D. Bradshaw, S. Woodward, W. Lewis, Angew. Chemie., Int. Ed. 2015, 54, 1417914182.

[9] N. J. Sweeney, J. Claffey, H. Müller-Bunz, C. Pampillón, K. Strohfeldt, M. Tacke, Appl. Organomet. Chem. 2007, 21, 57-65.

[10] L. Pasteur, Ann. Chim. Phys. 1850, 28, 56-99.

[11] Y. Tobe, Mendeleev Commun. 2003, 1-2.

[12] M. Marigo, T. C. Wabnitz, D. Fielenbach, K. A. Jørgensen, Angew. Chemie., Int. Ed. 2005, 44, 794-797.

[13] Y. Hayashi, H. Gotoh, T. Hayashi, M. Shoji, Angew. Chemie., Int. Ed. 2005, 44, 4212-4215.

[14] R. J. Comito, F. G. Finelli, D. W. C. Macmillan, J. Am. Chem. Soc. 2013, 135, 9358-9361.

[15] M. Asami, Bull. Chem. Soc. Jpn. 1990, 63, 721-727.

[16] J. Liu, L. Wang, Synth. 2016, 960-972.

[17] D. H. T. Phan, B. Kim, V. M. Dong, J. Am. Chem. Soc. 2009, 131, 15608-15609.

[18] J. Moritani, Y. Hasegawa, Y. Kayaki, T. Ikariya, Tetrahedron Lett. 2014, 55, 1188-1191.

[19] T. Suzuki, K. Ghozati, T. Katoh, H. Sasai, Org. Lett. 2009, 11, 4286-4288.

[20] D. B. Knight, J. A. Harrelson, J. Chem. Soc. Chem. Commun. 1987, 2, 116-117.

[21] R. M. Pagni, Found. Chem. 2011, 13, 131-143.

[22] P. Brewster, E. D. Hughes, C. K. Ingold, P. A. D. S. Rao, Nature 1950, 166, 179-180.

[23] S. M. E. D. Hughes, C. K. Ingold, J. Chem. Soc. 1935, 1196-1200.

[24] N. J. Sweeney, O. Mendoza, H. Müller-Bunz, C. Pampillón, F. J. K. Rehmann, K. Strohfeldt, M. Tacke, J. Organomet. Chem. 2005, 690, 4537-4544. 